\title{
DE LA «MUERTE FLORIDA» AL ACTIVISMO CIVIL: ELENA PONIATOWSKA ROMPE EL FUERTE SILENCIO ANCESTRAL
}

\author{
LINDA EGAN \\ University of California, Davis \\ UC-Mexicanistas
}

La noche de Tlatelolco (1971) -crónica fenomenal de testimonios sobre causas, sucesos y el momento culminante del Movimiento Estudiantil (la masacre de centenares de ciudadanos indefensos la noche del 2 de octubre, 1968)- se hizo un fenómeno literario casi al instante de su publicación. Y la Noche permanece como el texto clásico sobre esa epifanía en la evolución de la sociedad mexicana hacia el derecho de definirse como ciudadanía y estado modernos. Nueve años después de ganar esa ovación, Elena Poniatowska publica una colección de cinco textos que recogen testimonios y datos sobre la secuela violenta -lógica- de aquella matanza en la Plaza de las Tres Culturas. La antología se llama Fuerte es el silencio (1980), y la sorpresa es qué tan fuerte ha sido el silencio crítico alrededor de este libro fenomenal sobre los pasos que ciertos sectores del pueblo mexicano se atrevieron a tomar para distanciarse de un pasado y presente de criminalidad ancestral ${ }^{1}$. Estos individuos arriesgaban la vida al demandar a su gobierno la posesión de su humanidad, incluso mientras un agente de policía que torturaba a un hombre inocente afirmaba que «aquí no se trata de derechos» ${ }^{2}$.

En la primera crónica, son los desalojados, niños huérfanos o sobreviviendo simplemente en la calle como pueden, y los paracaidistas que engrosan el cinturón cada día más ancho de «ciudades perdidas» alrededor de la ca- pital (Poniatowska, Fuerte, p. 25), pobladas de millones de campesinos que llegan para no morirse de hambre o «desaparición» en la provincia y que encuentran que en la metrópoli corren los mismos peligros: hambre, falta de servicios, violencia, abusos oficiales, posible tortura, encarcelamiento, muerte.

Está, entonces, en su sitio la segunda crónica: «El Movimiento Estudiantil de 1968». Casi diez años después de esa tragedia nacional, Poniatowska echa una mirada retrospectiva a la vez que compacta y anecdótica sobre ese fenómeno. Al recorrer el contexto sociopolítico que enmarcaba el Movimiento, expone un inmejorable cuadro de costumbres del México pre-1968 a mitad de la centuria (Ibíd., pp. 34-42), todo un mito (México lindo y bonito), encubriendo así la realidad oscura y siniestra. La tercera crónica se enfoca en Rosario Piedra de Ibarra y su rictus de sonrisa, esa que lleva para enmascarar el duelo permanente que sufre porque agentes del gobierno de Luis Echeverría han torturado y «desaparecido» a su hijo. Poniatowska hace una crónica de las «malas» andanzas de Rosario y las 83 mujeres que se instalan en la Catedral del Zócalo para una huelga de hambre que protesta por la desaparición de sus hijos durante las guerrillas urbanas y rurales después del fin violento que Díaz Ordaz y Echeverría le pusieron al Movimiento Estudiantil. El gobierno manda soldados para acabar a la fuerza la huelga de

\section{Linda Egan}

Profesora en la Universidad de California, Davis, se ha especializado en literatura mexicana desde la colonia hasta el presente. Entre otras publicaciones destacan varias contribuciones dedicadas a sor Juana y su participación en el volumen del VI Symposium internacional de crítica literaria y escritura de mujeres de América Latina, sobre «Tragicomedia de la transgresión en Arráncame la vida», y sobre todo Carlos Monsiváis: Culture and Chronicle in Contemporary Mexico.
1

Carlos Monsiváis y Héctor Manjarrez escribieron artículos bastante nutridos sobre el libro a un año de su aparición, y hay varias reseñas. Entre otros escritos sobre Fuerte figuran breves comentarios incorporados en textos de análisis que abarcan otros textos de Poniatowska; casi inevitablemente, Fuerte recibe el comentario más sucinto, y el grueso de tales artículos se le dedica a La noche de Tlatelolco y/o Nada, nadie (sobre el temblor de 1985). Véanse, por ejemplo, los siguientes trabajos citados en la Bibliografía final: Volkow (reseña, 1981); Amar Sánchez; Beckman; Blanco (pp. 509-510); Fermán (pp. 161-62); Poot Herrera (pp. 18-19).

2

Elena Poniatowska, Fuerte es el silencio, México, Era, 1980 p. 138.

De la "muerte florida" al activismo civil: Elena Poniatowska rompe el fuerte silencio ancestral

LINDA EGAN 
3

Carlos Monsiváis, «'Mira, para que no comas olvido...': las precisiones de Elena Poniatowska», en La Cultura en México, 1007 (1981), p. 4.

4

Gabriela Mora, "Notas teóricas en torno a las colecciones de cuentos integrados», Revista Chilena de Literatura, 42 (1993), p. 133

5

Rocío Oviedo Pérez de Tudela, "Los cuerpos del disfraz. Madre o amante. La narrativa de Elena Poniatowska», Literatura Mexicana, 16 (2005), p. 163.

De la «muerte florida» al activismo civil: Elena Poniatowska rompe el fuerte silencio ancestral LINDA EGAN hambre y, aterrorizadas ante la posibilidad de ser desaparecidas como sus hijos, las madres desocupan la Catedral, pero no abandonan su búsqueda de la justicia.

En la cuarta crónica, Poniatowska como reportera reclama la voz protagónica, junto con varios testimonios, para detallar la historia de la práctica cruel de «desaparecer» gente: simplemente jamás dejar a nadie saber en dónde fue a dar, si está viva o muerta, como si fuera trapo o despojo de comida para los puercos. La quinta y última crónica ficcionaliza la fundación de la colonia proletaria cuyo nombre, Rubén Jaramillo, honra al campesino asesinado con su familia por agentes del gobierno en 1962. Con su propia voz de cronista casi del todo "callada», Poniatowska dramatiza lo que hemos aprendido en las cuatro crónicas anteriores a través del protagonista el Güero Medrano, líder revolucionario, mitad colonizador civil y guerrillero autosacrificial.

Para Carlos Monsiváis, uno de pocos críticos que ha comentado concretamente sobre esta obra de la cronista, dice que con su texto sobre los «desaparecidos» Poniatowska expone «la metamorfosis implacable» de un reportero que ha alcanzado un alto nivel de maduración. En la última de las cinco obritas, «La colonia Rubén Jaramillo», Monsiváis ve la mejor crónica conocida de Elena Poniatowska y uno de los textos definitivos de la literatura mexicana contemporánea. Allí los poderes descriptivos, el compromiso político y la calidad prosística se alían admirablemente para recrear una 'fiebre de oro' de nuestros días mexicanos: la invasión de tierras, la búsqueda masiva de casa propia ${ }^{3}$.

Me interesa resaltar otro comentario más de Monsiváis: en cierta medida, dice, los cinco textos de esta colección continúan explícita e implícitamente a La noche de Tlatelolco. De nuevo, el tema es la otra historia: las distintas fermentaciones del «espíritu del '68 o de la revolución latinoamericana, el destino de la disidencia extrema, las coincidencias y las disparidades entre quienes nunca han tenido voz y quienes se arriesgan (en diversas formas) con tal de romper el mutismo de siglos (Monsiváis, op.cit., pp. 2-3).

Al trazar en «Los desaparecidos» (Poniatowska, op.cit., pp. 138-80) "'la nueva y refinadísima forma de represión política’: la desaparición»-práctica gubernamental que no se confina a México, claro, sino que prolifera en sociedades premodernas doquier: a través del continente hispanoamericano y el africano (Ibíd., p. 138), Poniatowska ilustra el fenómeno con el caso de la radicalización de un muchacho mexicano que se une a la Liga Comunista 23 de Septiembre, dejándonos ver un proceso de causa y efecto: un gobierno violento y una clase media/sociedad indiferentes como motivo, una juventud enajenada y propensa a soluciones ideológicas aliadas a la violencia como consecuencia (Ibíd, pp. 14451). Este capítulo demuestra de modo muy claro el continuo entre Noche y Fuerte, vínculo inter e intratextual que nos ayudará ver que entre y dentro de las cinco crónicas de que consta la colección de 1980 se perciben estructuras externas e internas que se convierten en una «antología» de textos independientes al mismo tiempo muy articulados entre sí.

Ya no son nuevas las teorías de los cuentos integrados o de la novela compuesta. Estos subgéneros satisfacen al mismo tiempo las reglas de dos convenciones. De acuerdo con la primera y más obvia, los cinco textos de Fuerte es el silencio son crónicas individuales que pueden leerse de modo independiente. Claro, en términos generales, comparten en común un tema fácilmente percibido que gobierna su selección para reunirse en el mismo libro: llamemos este tema «la justicia». Casi desde los títulos -y la estructura externa de los textos - será posible ver la conexión entre ellos que inspira la decisión de recopilarlos.

De acuerdo con la segunda convención $-y$ ahora invoquemos una u otra de las teorías arriba mencionadas- algo habría que descubrirse enterrado más profundamente dentro de los textos que los uniera, lo que Gabriela Mora denomina "paradigmas de relación» ${ }^{4} \mathrm{y}$ lo que en este estudio identifico como leitmotivs $\mathrm{u}$ otros elementos verbales/estilísticos aparentes en la «escritura palimpséstica» ${ }^{5}$ de Poniatowska. La interrelación de las crónicas de Fuerte destaca la eficacia de su denuncia periodística de opresión, miseria, criminalidad impune -el mensaje evidente en la superficie- y la potencia de su mensaje más trascendente, el que subyace como símbolo y poesía prosaica. Éstos liberan sus lecciones en estructuras prefigurativas y analépticas que más sutilmente amarran los textos para rendir, en su conjunto, un impacto emotivo avasallador. Esta impresión rompe el silencio ensordecedor de una sociedad que por demasiados siglos ha vivido, sumisa y abúlica, bajo el yugo de un estado criminal que impunemente azota a los que debe servir y cuidar.

El motivo simbólico más evidente en el palimpsesto que corre bajo la superficie de los cinco discursos puede definirse como el 
síndrome azteca, el conjunto de características culturales heredadas desde antes de la llegada del europeo y que sigue motivando, modelando, mortificando -y matando- a líderes (mártires) y pueblo en lo que Jean Franco ha caracterizado como su «viaje circular o frustrado» ${ }^{6}$. $\mathrm{O}$, para ponerlo en términos más universales, en pleno siglo $\mathrm{XX}$, cualquier gobierno que se vale de la violencia bruta, como lo hizo el de Díaz Ordaz antes de los Juegos Olímpicos de 1968 y Echeverría en 1971 durante su época de «Apertura Democrática», es simple y obviamente arcaico, premoderno’:

In the case of France in the seventeenth century, the shift from brute force to symbolic representations of power was an important contribution to the eradication of violence....[En el caso de México en el siglo XX,] the very deployment of force produced the crisis of legitimation: what was lost by the government of Díaz Ordaz was authority (Sorensen, op.cit., p. 303).

En su estudio del tratamiento de la masacre de Tlatelolco hecho por Octavio Paz y Elena Poniatowska, Diana Sorensen se detiene en el análisis paciano de lo prehispánico que caracteriza el México contemporáneo:

In a dazzling explanation of the Aztec worldview, Paz leaves no loose end: every element in the structure is held together by the centripetal pull of the conceptual axis he deploys. In the center lies the sun, which demands blood through the centuries, following the rule of continuity, which permeates time and space. ... Furthering the logocentric organization of the argument is the weight of the name: the repetition of the Mexica name for both the nation and capital city reinforces the haunting, unavoidable presence of the «terrible dominación azteca» (Ibid., p. 308).

Sorensen finalmente ve en la lógica de Paz un nivel de rigidez arcaica reflejada en su propio argumento acerca de la herencia azteca; por mi parte, acepto hasta cierto punto el razonamiento de Paz y el de Sorensen. Sin embargo, lo que veo como el «síndrome azteca» en Fuerte es el silencio -y una notable proporción de la literatura mexicana desde la conquista hasta hoy- no está definido por conceptos poéticos: el sol hambriento de sangre, etc. ${ }^{8} \mathrm{Mi}$ interés en la concatenación de características premodernas que se ostentan con regularidad en los cinco textos de Fuerte es cómo el discurso periodístico de Poniatowska los yuxtapone con signos de cambio, y más, con la índole novedosa de los que aportan las propias transformaciones.

Diré como preludio a mi análisis y parte del enfoque popular-ancestral de este estudio, que importa mencionar la voz misma de Poniatowska ya que, según un crítico temprano del

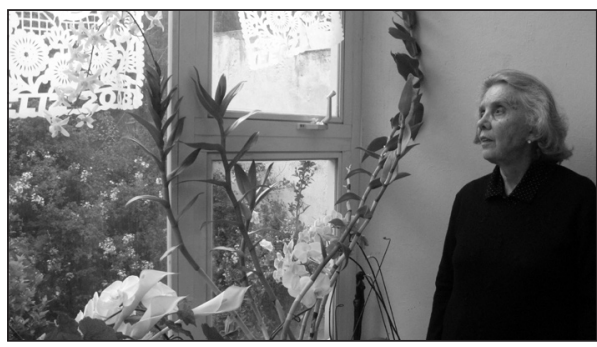
libro, la primera crónica, sobre los niños pobres y migrantes a la ciudad, es la pieza menor de los cinco, por su falta de ironía, su tono sincero y popular, el afecto antiguo de la autora por los marginados, y la frase feliz, «de la cual Carlos Monsiváis es el mejor practicante sin duda [y que] corresponde al uso del intelecto»9. Dice Héctor Manjarrez que Elena Poniatowska es sentimentaloide $y$, para mayor pecado, parece estar entrando ilegalmente en propiedad verbal que pertenece por derecho intelectual a su colega o, peor aún, degradando a la misma por gorjear frases demasiado «felices» para ser suficientemente inteligentes.

Al volver a leer el libro, presté atención particular al tono de voz de la primera pieza y especialmente a lo que Manjarrez considerara sus «frases felices». Y aunque sí hallo que es «menor» en comparación con las otras cuatro, no es por la calidad de la voz narrativa sino porque en muchos otros medios hemos ya podido informarnos acerca de la gente pobre de la gran capital de México - pero enfatizo aquí que pocas veces con tanto colorido, tanta «frase feliz», tanto «uso del intelecto» y tanto sabor verbal como en este cuadro pintado por Poniatowska. Esas frases que molestan a Manjarrez no son tanto felices como lo son aforísticas y no se confinan a la primera crónica sino que siembran liberalmente el discurso del libro entero ${ }^{10}$. Los otros cuatro capítulos son insólitos.

En casi ningún otro lugar (en 1980) habíamos leído de una mujer que solita acecha al presidente del país en cualquier esquina, insistiendo que le diga dónde tiene a su hijo, dónde lo está torturando; sobre ochenta y tres mujeres pobres venidas de todas partes de México y que, privándose de comida en la Basílica, llaman la atención de un público absolutamente indiferente a las fotos de docenas de adolescentes desaparecidos, torturados, probablemente asesinados por el gobierno. Tampoco leído estadísticas de las que ni la autora quiere enterarse, no vaya a tener que aceptar que su México lindo y querido no es más que cualquier otra dictadura barata;
6 Jean Franco, Historia de la literatura hispanoamericana a partir de la Independencia, trad. Carlos Pujol. $7^{a}$ ed., Barcelona Seix Barral, 1987, p. 30

7

Diana Sorensen, «Tlatelolco 1968: Paz and Poniatowska on Law and Violence», Mexican Studies/Estudios Mexicanos, 18 (2002), pp. 293 y 303.

8

Está basado en lecturas minuciosas de Sahagún y muchos cronistas de Indias, incluyendo a Tezozómoc, Ixtlilxóchitl y otros escritores indígenas, más una gran cantidad de investigación crítica y teórica (la religión comparada, un estudio sostenido de la cultura mesoamericana y de la literatura, sociopolítica y cultura popular mexicanas desde la conquista en adelante)

9

Héctor Manjarrez, «La indiscreción de Elena Poniatowska». Cuadernos Políticos, 30 (1981), p. 104

10

Ya que acabo de escribir un libro que reúne los aforismos de la obra entera de Carlos Monsiváis, ahora me hallo contemplando los aforismos genia les de la «sentimental» Elena Poniatowska.

De la «muerte florida» al activismo civil: Elena Poniatowska rompe el fuerte silencio ancestral LINDA EGAN 


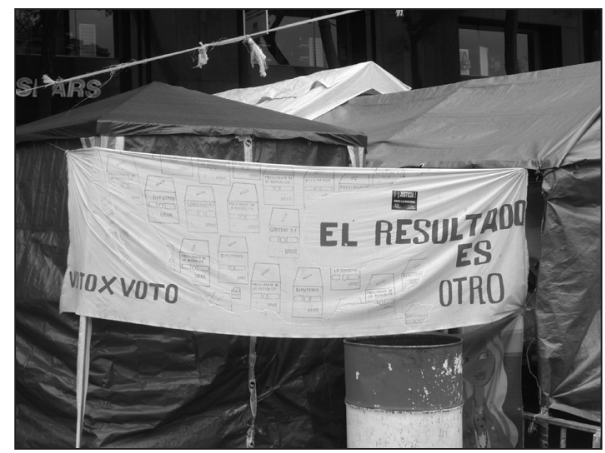

Plantón en el Zócalo.

11

Carr dice que fueron 10.000 paracaidistas.

12

Elena Poniatowska nació en París, hija de madre mexicana cuya familia salió de México durante la Revolución Mexicana para refugiarse en Europa; allí se casó la madre de Elena con un príncipe polaco. Hasta mediados de la Segunda Guerra Mundial, cuando las condiciones de Francia obligaron la huida de la familia Poniatowska Amor a México, Elena se educó como niña francesa de la alta burguesía europea.

13

Magdalena García Pinto, «Elena Poniatowska». Entrevista, in Women Writers of Latin America: Intimate Histories. Trad. Trudy Balch \& Magdalena García Pinto. Austin: University of Texas Press, 1991, pp. 162-81.Entrevista con Elena Poniatowska de 1991 en español traducida al inglés; ésta y otras traduccione de la entrevista (de nuevo al español) son mías.

14

En una reseña positiva de Fuerte, la escritora Verónica Volkow alaba la "gran valentía y [su]... insuperable calidad literaria» (Volkow, op. cit., p. 42), pero inmediatamente después califica su propio juicio al decir que el valor de la colección como testimonio «rebasa infinitamente cualquier consideración de valor literario». Al preguntarme por qué a los críticos en México pareciera siempre más importante lo testimonial que lo literario me contesto a mí misma: precisamente por el análisis que llevo a cabo en este estudio. Pero que conste: no estoy de acuerdo

De la «muerte florida» al activismo civil: Elena Poniatowska rompe el fuerte silencio ancestral LINDA EGAN

ni leído de cómo una espiga de campesino mesiánico casi solo $\mathrm{y}$ de una noche al día siguiente persuade a 15, 000 indigentes a mudarse a un terreno vacío (del que se ha adueñado un terrateniente) y poblarlo para nunca jamás salir, pese a invasiones de policías, soldados y gobernadores, amén de encarcelamientos, torturas y asesinatos de colo$\operatorname{nos}^{11}$. Vienen. Se quedan. Esta casa es suya.

Y ¿aquella voz sentimental y demasiado «sincera» de la primera crónica? No es ninguna voz literaria ni asumida para demostrar solidaridad con el pueblo sufrido. Es la voz de su Alteza Mexicana la princesa populachera Poniatowska quien a los diez años de edad llegó a la Ciudad de México, hablaba sólo francés ${ }^{12}$ y fue inscrita por sus padres en «una ridícula primaria británica, donde -dice- cantábamos 'God Save the Queen'» ${ }^{13}$. Y ya que nunca antes había estudiado formalmente el idioma español, aprendió la lengua de los sirvientes de la casa:

Desde aquel tiempo, siempre he guardado mucha compasión para las criadas de la casa o como quieras llamarlas. Eso explica por qué me gusta tanto Jesusa Palancares, la protagonista de mi libro Hasta no verte, Jesús mío. Aprendí español porque no me hacía falta hacerlo. Hasta cierto punto, se le consideraba el idioma del colonizado....De hecho, hasta hace poco, yo todavía empleaba ciertas expresiones comunes entre la gente de poca escolarización. (citada en García Pinto, op. cit., pp. 168, 170)

Pese a su abolengo aristocrático, Poniatowska se identifica con los subalternos de México y desde su niñez habla con el mexicano callejero. Por eso no digo, como tantos

con Volkow. El valor críticopolítico es de enorme valor y cuenta como parte de su mérito literario; explica en gran medida por qué este libro retiene su legibilidad después de 28 años y todavía está disponible en amazon.com. Pero nadie lo leería si antes que nada aquel testimonio no estuviera enfundado en un discurso de inmejorable fuerza y delicadeza poética: si la técnica y la voz literarias de Elena Poniatowska no fueran de primer orden, insuperables entre los mejores escritores en lengua española entonces $y$ hoy. otros en coro, que ella «da voz a los que no la tienen» sino que habla con los que sí tienen voz - un habla rica, colorida, fuerte- pero que por el terrorismo estatal suelen mantenerse quietecitos hasta que alguien como Poniatowska les da el micrófono en forma de un libro como Fuerte es el silencio. A veces es excelente ser princesa de a de veras, aunque hable como si hubiera nacido en la Candelaria.

Comienzo, entonces, a juntar los hilos que integran los cinco segmentos de lo que es, además de una antología de textos de periodismo literario, una sola crónica de vasto valor testimonial y de encumbrado mérito estético $^{14}$. Esta crónica plantea una visión singular del México de los sesenta examinado desde diversos ángulos pero por un par de ojos enfocado en un solo sujeto: una sociedad suspendida tortuosamente entre épocas. Por un lado se nos presenta un pueblo todavía regido por una cosmovisión que sintetiza la religión arcaica (pagana) y la histórica (cristiana): México desde la conquista, a través de la colonia y hasta hoy hecha de gente premoderna pero arreglándosela dentro de una sociedad «histórica» ${ }^{15}$. Por otro lado, un México persuadido desde sus orígenes en Anáhuac de la inescapable «necesidad dolorosa de la desigualdad social» (Clendinnen, op. cit., pp. 23940, ésta y seguidas traducciones mías) y, por lo tanto, de ritos y reglas inquebrantables en todos los niveles reforzados so pena de muerte para dramatizar el rigor de la conformidad y para mantener un orden inherentemente precario, siempre a punto de desintegrarse ${ }^{16}$. «Cualquier inconforme es un enemigo, su familia también y un día sin más, de pronto, deja de estar entre nosotros» (Poniatowska, op. cit., p. 138).

El período colonial sólo transformó el autoritarismo de la sociedad azteca, refinando y prolongando tendencias de su carácter habituado desde siempre en el pueblo mexica: «una profunda predilección cultural...por la auto-extinción», la pasividad, el alcoholismo, el ritual como «un espejo ancho y oscuro» en el que una sociedad todavía no está hecha, sino que siempre está en vías de constituirse, consciente de la fragilidad de lo "construido» vs. lo «fijo» y la índole no acabada de su país (Clendinnen, op. cit., pp. 259-60). A pesar de la retórica tranquila de los agentes municipales, Tenochtitlan «era un lugar asombrosamente violento, en donde mucha de esa violencia no era ni individual ni sin planearse, sino certificada y oficial» (Ibíd, p. 46). Y no 
se confinaba a los sacrificios rituales sino que regularmente se desataba sobre los ciudadanos, incluso hasta el punto de la muerte (Ibid., pp. 46-47).

La lección que más se quedaba con los mexicas a través de los siglos después de la conquista fue que las sangrientas ceremonias de carnicería sacrificial, a las que se habían regalado sus enemigos, sus esclavos, sus vecinos y sus propios hijos, no habían salvaguardado el orden social ni su universo sino solamente habían confirmado que ellos mismos -los seres humanos- eran un tiempito «hecho» de «dependencia desoladora» de las condiciones inhumanas, vegetales, de la existencia fugaz (Ibíd., pp. 262-63) $)^{17}$, de «la falta de realidad de la persona humana»18. Quizás el aspecto que más disguste al que escucha hoy de los sacrificios humanos de Mesoamérica (o bien de los incas o cualquier otra gente: africanos, hindúes...) es el elemento del sufrimiento -de la tortura- que figuraba como parte inherente del rito.

Los toltecas y los aztecas convirtieron lo que originalmente había sido un rito sagrado en un acto político-económico ${ }^{19}$. Un aspecto del asesinato ritual entre los mexicas, en ese entonces, combinaba la purificación espiritual y la prueba del poder teocrático, fenómeno que requería del sufrimiento de la víctima, incluso cuando era un acto de autosacrificio, como en el caso de los danzantes de Chiapas quienes, por lo menos hasta el momento a mediados del XX cuando Samuel Martí escribió su estudio, todavía bailaban sobre cenizas calientes, quemándose los pies y luego emborrachándose hasta perder el sentido (Martí, op. cit., pp. 234, 58). Como reza la canción prehispánica, «Xopancuícatl, xochicuícatl», los flechadores deben hacer que sus dardos entren en el cuerpo del mancebo «impoluto, virgen, hombre», amarrado a la «columna pétrea pintada» sólo un poco: «no es necesario / que pongas toda tu fuerza para / asaetearlo, para no / herirlo hasta lo hondo de sus carnes / y así pueda sufrir / poco a poco, que así lo quiso / el Bello Señor Dios»²0. En Tenochtitlan, al tlatoani-rey se le consideraba la personificación en la tierra del Bello Señor Dios, y lo que daba placer a Huitzilopochtli o a Tláloc igual complacía a Ahuítzotl o Moctezuma.

Este escenario cultural-psíquico se lleva a cabo en un territorio fuertemente urbanizado, donde todo está dominado por el quincunce, los cuatro rumbos de la periferia subordinados como tributarios al centro del poder

político, económico y religioso (Séjourné, op. cit., pp. 101-109). Desde que las tribus nómadas comenzaron a asentarse y a desarrollar la agricultura, México ha sido una tierra de gran población, la mayoría de la cual ha estado siempre concentrada en el centro del país, donde, por consecuencia natural, incluso en tiempos de las grandes civilizaciones maya y azteca, se

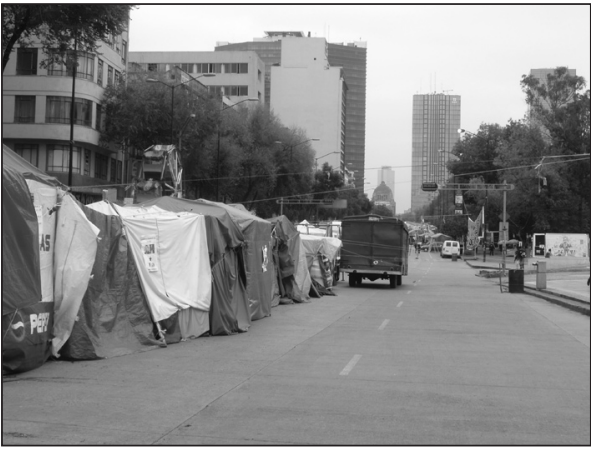
sufrían estragos medioambientales (Stevens). En Morelos, donde se considera que la tierra es excelente para labrar, hay un «aluvión de gente» que, paradójicamente, da lugar a la fragmentación excesiva de la tierra y, por consecuencia, al empobrecimiento; todo esto unido a una gran cantidad de hombres armados que van cazando a campesinos de parte de terratenientes y funcionarios del gobierno, sembrando así un ambiente permanente de terror, machismo y venganza.

En el contexto de este retrato abreviado de la cosmovisión ancestral e histórica mexicanas, iremos viendo cómo en Fuerte es el silencio Poniatowska pone en oposición a ese síndrome arcaico e hiriente, a esas dos fuerzas poderosas:

(1) Frente a la violencia implacable, casi impensable, del gobierno y sus agentes hacia no sólo los acusados de delitos sino a las familias y demás ciudadanos, y a la indiferencia y apatía casi igualmente incomprensibles de la mayoría de la gente, la cronista primero levanta ante los ojos de todos -un gobierno cínico, una sociedad entumecida y nosotros los lectores escandalizados y conmovidos- el rechazo absoluto de un individuo que se opone a la violencia oficial y a la sumisión civil. En la persona de Rosario Piedra de Ibarra, madre de uno de los centenares de «desaparecidos» mexicanos, Poniatowska modela para México una democracia ideal, cuyo infatigable asalto pacifista y legal contra la corrupción institucionalizada, la violencia gubernamental y la indiferencia social por el valor de la vida humana ilumina desde dentro de la antorcha espiritual que es esta madre adolorida,

17

La analogía que corre a través de todas las descripciones mexicas del crecimiento $y$ desarrollo humanos equipara plantas y seres humanos; en particular; desde su nacimien- to hasta su madurez, al ser humano se le compara a una mazorca de maíz (Clendinnen, op. cit., p. 181) Durante los ritos sacrificiales, el cuerpo humano sirve como accesorio teatral (lbíd, pp.
73-74). El efecto, en conjunto, de las prácticas sagradas, políticas y sociales es la deshumanización y entumecimiento del humano, para que acepte su lugar en la jerarquía rígidamente controlada $\sin$ queja ni cuestionamiento (Samuel Martí, Canto, danza y música precortesianos, México, Fondo de Cultura Económica, 1961 , p. 234), incluso hasta la entrega de un hijo para ser sacrificado y comido (Fray Bernardino de Sahagún, Historia general de las cosas de Nueva España, Madrid: Alianza Universidad, 1988, 1, p. 104). El sacrificio de niños se practicaba en Mesoamérica ya desde 200 a.C.-600 d.C., época del estado-ciudad de Teotihuacan, cultura «madre» de Tula y luego de Tenochtitlan (Johanna Broda, «Templo Mayor as Ritual Space», en Johanna Broda, Davíd Carrasco y Eduardo Matos Moctezuma, The Great Temple of Tenochtitlan: Center and Pe riphery in the Aztec World, Berkeley, University of California Press, 1987, p. 88)

18

Laurette Séjourné, Pensamiento y religión en el México antiguo México y Buenos Aires, Fondo de Cultura Económica, 1957, p. 59.

19

Clendinnen, op. cit., pp. 260 61: Laurette Séjourné, Pensamiento y religión en el México antiguo, México y Buenos Aires, Fondo de Cultura Económica 1957, p. 172.

20

Miguel León-Portilla, Literaturas indígenas de México. México, Editorial MAPFRE/ Fondo de Cultura Económica, 1992, p. 258 .

De la «muerte florida" al activism civil: Elena Poniatowska rompe el fuerte silencio ancestral LINDA EGAN 


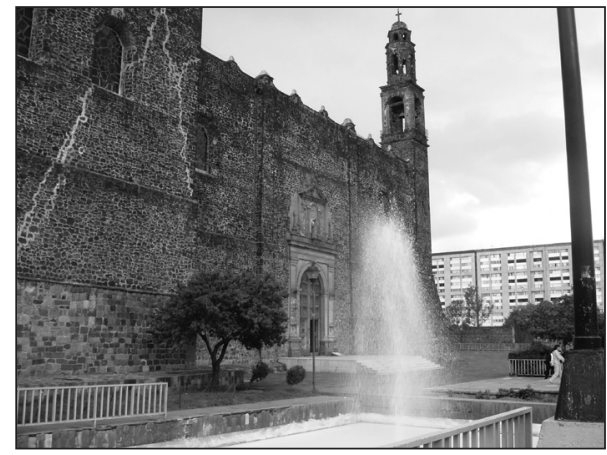

Plaza de Tlatelolco.

21

Carlos Monsiváis, Entrada libre: crónicas de la sociedad que se organiza, México, Era, 1987 p. 41.

22

Coyoxauhqui, en mitos aztecas, es diosa de la luna y la Vía Láctea, y hermana de Huitzilopochtli, dios del sol y la guerra, quien, no bien nace (saltando del vientre de su madre, Coatlicue-Cihuacóatl en la Montaña Coatepec), le corta la cabeza a su hermana celosa y le da una patada que la manda rodando montaña abajo hasta que se despedaza al pie de la colina. Estos elementos se replican luego en los ritos sacrificiales del Templo Mayor, un Coatepec simbólico. Un enorme disco esculpido de la diosa despedazada se puede ver en el museo del Templo Mayor excavado al lado de la Catedra en el Zócalo de la Ciudad de México. Sobre el mito del nacimiento de Huitzilopochtli y la muerte de su hermana, véase, por ejemplo, Richard Townsend The Aztecs, London, Thames and Hudson, 1992, pp. 58, 60.

23

En Cempoal, donde Cortés hizo aliado al Cacique Gordo, primero derrocó los ídolos del templo que allí encontró embadurnado de la sangre de los sacrificados y cuando los indígenas vieron sus ídolos «hechos pedazos, los caciques y papas [sacerdotes] que con ellos estaban lloraban y tapaban los ojos» (Bernal Díaz del Castillo, Historia verdadera de la conquista de la Nueva España, México, Alianza, 1991, p. 131).

De la «muerte florida» al activismo civil: Elena Poniatowska rompe el fuerte silencio ancestral LINDA EGAN una Ausencia Fundamental en México: el Vacío donde los derechos humanos deben estar y ser reconocidos, respetados y poseídos.

(2) A la misma violencia histórica e interminable desatada contra los campesinos indefensos, Poniatowska nos ofrece el caso aleccionador de un revolucionario rural, maoísta entrenado en China que radicaliza a quienes puede, y que se vuelve experto en organizar invasiones de terrenos por miles de paracaidistas, estableciendo ciudades proletarias como golpe de relámpago antes de que las autoridades lleguen para desalojar a las masas. Aquí el ejemplo es el infatigable asalto -violento e ilegal-contra la misma corrupción institucionalizada, el mismo gobierno violento y la oligarquía rapaz, esto es, la misma actuación deshumanizadora. El héroe popular, el Güero Medrano, no quiere menos que Rosario Ibarra: vida y derechos humanos. Parece que pierde la vida, pero gana derechos y vivienda para muchos miles de pobres en el campo, sin que la mayoría de ellos tengan que volverse violentos como él.

Poniatowska da comienzo a su crónica con «Ángeles de la ciudad», concentrándose en la vida de miseria de los campesinos que entran a raudales en la capital mexicana; huyen del desastre rural fabricado por un gobierno centralista que, desde tiempos de Teotihuacan, Tula y Tenochtitlan, sigue basando su economía imperial sobre el sistema tributario que arrebata de la periferia lo que alimenta a la capital todopoderosa. Mientras Carlos Monsiváis condena «la centralización del poder que es la sacralización del despilfarro de recursos» ${ }^{21}$, Poniatowska fija su ojo en el efecto del sistema tributario sobre la gente de una ciudad ideada como «fauces del monstruo...que todo lo envilece» (Poniatowska, Fuerte, p. 32) y en el propio Ángel de la Independencia, símbolo libertador que por el cinismo del gobierno ladrón y matón se ha «disfrazado de zopilote negro» (Ibíd., p. 33). Los niños que pepenan montones de basura están pintados de negro por el smog, y sus figuritas resaltan contra el fondo del «compos» grueso llamado «rico suelo» que se utiliza en la agricultura y las áreas verdes de la capital, «o, para decirlo en términos elegantes, es una sopita de nuestro propio chocolate. El círculo se cierra. Nos alimentamos, evacuamos y volvemos a alimentarnos» (Ibíd., p. 25).
Visión, en fin, arcaica, del cosmos sagrado en el que el ser humano, el animal, el vegetal y el cuerpo celestial, todos ellos tenían el mismo valor y se sostenían entre sí en un circuito de interdependencia.

En el Centro, los periféricos esclavizados por la falta absoluta de empleo, vivienda, servicios municipales -la más mínima atención del Padre Tlatoani- buscan consuelo donde lo encuentren. Por ejemplo, cuando un terremoto derrumba el Ángel dorado de la Independencia, icono de la libertad y del bienestar que vinieron esperanzados a buscar, Poniatowska personifica la estatua rota, cual Coyolxauhqui despedazada por fuerzas cósmicas ${ }^{22}$ : una beata, «entre gruesos lagrimones murmuraba: 'Se ha muerto mi Ángel de la Guarda'». (Poniatowska, Fuerte, pp. 13-14 ${ }^{23}$. No habla Poniatowska. Habla la gente desamparada que Sahagún cita en su gran crónica; habla la gente desamparada hoy día en la Ciudad de México que Poniatowska escucha. Las extremidades y alas del Ángel son mandadas a talleres en los barrios más pobres, y la gente derrotada que venera a la diosa vencida acude a vigilar su rearticulación, como si, tras casi cinco siglos de espera, fueran a ver el milagroso retorno de los dioses que la habían abandonado de su calpulli en Tenochtitlan:

Tuvo muchos visitantes en su cuarto de enfermo... Cientos de curiosos se asomaron a verlo, a comprobar lo que el tiempo hacía con sus cicatrices; hubo pleitos en los vecindarios por su posesión; los habitantes de las calles de doctor Liceaga y de doctor Barragán estaban muy orgullosos de que el nuevo Ángel, más grande y mejor dorado, surgiera de los andrajos de su colonia (Poniatowska, Fuerte, p. 14).

Poniatowska da fin a su crónica con «La colonia de Rubén Jaramillo», nowvelle testimonial que ficcionaliza dramáticamente y en detalle minucioso, a manera de Hasta no verte, Jesús mío, el nacimiento, la infancia y adolescencia de una sola de esas «ciudades perdidas» que surgen como hongos en la noche, llenándose de tantos pobres campesinos, tan rápida y tercamente que no hay voluntad ni fuerza militar que los regrese a su pueblo anterior, "conflictivo, hambriento y explotado» (Ibíd., p. 224). ¿Algo distinto al siglo XVI?:

En este mundo no hay verdadero placer ni verdadero descanso, mas antes hay trabajos y aflictiones y cansancios estremados, y abundancia de miserias, 
pobrezas. ¡Oh, hija mía, que en este mundo es lugar de lloros... donde hay fríos y destemplanzas... y es lugar de hambre y de sed!... Este mundo es malo, penoso $0^{24}$.

El tema de los campesinos -lo que ocupan terrenos baldíos cerca de Cuernavaca- desesperados pero movilizados hacia un futuro mejor, reúne los cinco textos del libro como cinturón de miseria, rabia y aprendizaje que acaba por desenlazar un nudo eterno y halla anidado muy adentro un hilo delgado que se alinea hacia una historia nueva.

En medio, tres crónicas que fundamentan el viaje desde Anáhuac hasta la esperanza en 1980 de que los mexicanos pronto habiten una capital y un país -una sociedad- plenamente situada en el Nuevo Tiempo Mexicano. El recorrido del Movimiento Estudiantil refuerza un hilo que corre a través de la colección entera: el que ata la voluntad férrea de «la sagrada imagen presidencial» (Poniatowska, Fuerte, p. 50) a la voluntad sumisa de todos los mexicanos que obedecen; es mejor simplemente no prestar atención a la política, aceptar pasivamente lo que el Primer Mandatario dicte porque ¿qué caso tiene oponerse o siquiera expresar una opinión contraria? Niiiiiiii moooooooooooodo.

El presidente es el padre, nuestro papacito, y en el 68 nos tocó, ... un padre colérico que tomó una silla para romperla en la cabeza y así matar al hijo desobediente. Todos conocen las consecuencias de la cólera y el miedo gubernamentales; un número aún no establecido de estudiantes, hombres, mujeres y niños (325 según el periódico inglés The Guardian) cayeron asesinados en la plaza de las Tres Culturas el 2 de octubre de 1968 (Ibid., p. 51) 25.

\section{Otra vez Sahagún:}

¡Señor nuestro, humanísimo! En vuestras manos me pongo totalmente porque yo no tengo posibilidad para regirme ni gobernarme, porque soy ciego y soy tiniebla, y soy un rincón de estiércol....Está la pobre gente sin padre y sin madre, huérfanos, que no saben ni entienden, ni consideran lo que conviene a su pueblo... Están como mudos. No saben hablar; están como un cuerpo sin cabeza (Sahagún, op. cit., 1, pp. 335-36).

No así Elena Poniatowska, ni el mínimo número de héroes que rompen la mudez de siglos de terrorismo estatal. Taladrando con sus ojos a Díaz Ordaz en 1977, instalado nada menos que en el Zócalo en 1977 «en insolente conferencia de prensa al ser nombrado por el nuevo presidente López Portillo embajador de México en España» (Poniatowska, Fuerte, p. 71), y mientras el ex presidente y autor de la matanza de Tlatelolco reinventa la historia descaradamente, Poniatowska observa cómo «metió sus manos de nuevo en la herida de Tlatelolco y retó groseramente a sus interlocutores: ¿¿Dónde están los cientos, los miles de muertos, señores periodistas?'» (Ibíd., p. 71). En primera instancia, la cronista ha hecho reaparecer en el centro de Tenochtitlan-México, junto al recién excavado Templo Mayor (1978-1982), la figura ensangrentada del tlatoani-sacerdote azteca en persona de Díaz Ordaz, sus manos hundidos en el pecho del Movimiento-Víctima sacrificado por él y sus soldados, cuyas balas destrozaron el corazón del empeño democrático de los estudiantes.

En segundo lugar, la pregunta arrogante y realmente grosera del hombre a quien, impunemente, será premiado por el gobierno por su crimen, se refiere a un leitmotiv poderoso de Fuerte es el silencio: los jóvenes rebeldes «desaparecidos» por el gobierno porque se atrevieron a disentir de la Palabra Divina del tlatoani, a quien «se consideraba...como parte fundamental del universo,...y se pensaba que para la armonía del universo era imprescindible la presencia del gobernante supremo» ${ }^{26}$. A la mañana siguiente después de la matanza del 2 de octubre, 1968, sólo quedaban en la Plaza de las Tres Culturas unos zapatos y manchas de sangre, las condiciones perfectas para que el gobierno negara la realidad, que "aquí no pasa nada, no pasó nada, el gobierno es la víctima, los estudiantes y agitadores comunistas quieren arruinar los Juegos Olímpicos y el prestigio del Primer Mandatario, ja la prisión con todos!» y así fue...con la salvedad de que unos cuantos, como Elena Poniatowska, Carlos Monsiváis, Rosario Castellanos, Carlos Fuentes y Octavio Paz, escribieron, denunciaron, dimitieron embajadas.

Los cadáveres que de la noche a la mañana desaparecieron de la plaza de Tlatelolco y los que años después desaparecieron dentro de los muros de la prisión de Lecumberri (donde Elena iba todos los días para recoger sus testimonios) figuraron entre los primeros. Luego se iban esfumando los de los setenta que se habían radicalizado, uniéndose a grupos comunistas, bandas de guerrilleros, o bien simplemente se habían ido caminando por la calle, hablando con amigos, leyendo ciertos libros y ipum! sospechados, agarrados por la
Fray Bernardino de Sahagún, Historia general de las cosas de Nueva España, intr. Alfredo López Austin y Josefina García Quintana. Madrid: Alianza Universidad, 1988, 1, pp. 365-66.

25

Meyer y Sherman dicen que los mexicanos más informados coinciden en figuras entre 300 y 400 muertos (Michael Meyer, D., \& William L. Sherman. The Course of Mexican History. 4a ed. New York- Oxford, Eng.: Oxford University Press, 1991 p. 669).

26

José Alcina Franch, "Poder y sociedad», Azteca-Mexica: las culturas del México antiguo, José Alcina Franch, Miguel LeónPortilla y Eduardo Matos Moctezuma (eds.), Barcelona y $\mathrm{Ma}^{-}$ drid: Lunwerg Editores, 1992, p. 164.

De la «muerte florida" al activism civil: Elena Poniatowska rompe el fuerte silencio ancestral LINDA EGAN 
Los mesoamericanos asignaban valores humanos y religiosos simbólicos a papelitos de colores con los que decoraban por igual ídolos de dioses, los cuerpos de víctimas sacrificiales y los cadáveres de gente recién muerta, 0 por sacrificio u otras causas.

De la «muerte florida» al activismo civil: Elena Poniatowska rompe el fuerte silencio ancestral LINDA EGAN policía (fuerzas de «seguridad») y ya, jamás vistos ni oídos nunca. Gone in Sixty Seconds.

Rosario Ibarra parpadeó y perdió de vista para siempre a su hijo Jesús; luego se construyó una caparazón de dureza suficiente que la protegería durante los años de su larga campaña contra la impunidad del presidente y sus verdugos, contra la criminalidad del gobierno, contra la im-pasividad de sus compatriotas -sobre todo los de su misma clase burguesa- y contra la deshumanización de su sociedad y la desvalorización de la vida de un muchacho, un hombre, una mujer, una joven. Toda esta situación reclutó a Elena Poniatowska, quien se presta a sus lectores como abogada del diablo, como modelo de disidente demócrata; es ella quien cuestiona todo lo que hace y dice Rosario Ibarra contra su gobierno, no vaya a acusar a éste de crímenes y atrocidades que no pueden ser-simplemente no es posible que sean- verdad.

Y cuando resulta que sí lo son, la doble prueba -la de las acciones de Rosario y la voz de Poniatowska- deja a todos sin más opción que ver con los lentes más enfocados del mundo la pura pura realidad. En el México de la década de los setenta, igual que la Uganda de Idi Amín, la Argentina del militar que desaparece a miles, igual que en cualquier dictadura violenta, igual que en el Tenochtitlan sacrificial de Moctezuma, los que son secuestrados, torturados y escondidos de sus familiares y amigos son tratados así porque «no importan, porque bien pueden ser cuarenta o cuatrocientos o cuatro mil, porque no son nadie» (Poniatowska, Fuerte, p. 73), porque son «como papelitos de colores» (Ibid , p. 90)27. Del muchacho desaparecido, «nadie sabe cuál es su condición física, si está enterado de que su madre lo busca, de que muchos mexicanos se indignan contra un procedimiento degradante de la persona humana» (Ibíd., p. 98). Si en otros países por lo menos se documentan los cargos en contra de un prisionero, en México «no hay cargos, el opositor simplemente se desvanece, nadie sabe, nadie supo... El desaparecido... ya no es nadie, no es nada. El desaparecido se lleva hasta su silencio» (Ibid., p. 139).

Rosario está incendiada. Arde. Toda la noche. Arde como lámpara votiva. Nunca he visto a un ser tan absolutamente trabajado por el sufrimiento como Rosario, pero trabajado en el sentido que la ha pulido, la ha adelgazado hasta ser casi puro espíritu, pura fuerza de voluntad vuelta hacia el hijo (Ibid., p. 101).
El sufrimiento. La tortura. El sacrificio. La trinidad sagrada de la teocracia mesoamericana. En ella estaba basada la ideología cultural, económica y política. Y Rosario Ibarra, sinédoque de todos los padres que sufren «la tortura moral» (Ibid., p. 113) por sus hijos secuestrados y torturados por violación sexual, asfixia, sed, ahogo, toques eléctricos, golpizas, incomunicación total, privación de toda necesidad física y psíquica, quemaduras, patadas, la desnudez, puñetazos... (Ibíd., pp. 105-15). Obligan a los niños observar las torturas de sus padres e incluso a una madre presenciar la tortura de su hija de año dos meses (Ibíd, p. 113).

De Sahagún («En Tenochtitlan, las madres tenían que observar a los sacerdotes pellizcar a sus niños para que soltaran lágrimas -buen augurio para la lluvia- y luego mientras los degollaban y cocían para comer») a la cruda realidad de otros tiempos:

A mi hijita Tania, de un año dos meses, la torturaron en mi presencia maltratándola y aplicándole toques eléctricos en todo su cuerpecito, después de haberla torturado psicológicamente al ver golpear a sus padres. Recuerdo y me estremezco al hacerlo, cómo lloraba y gritaba 'Papá' y mi dolor ante la impotencia para defenderla y consolarla. ...Cuando fui liberada, antes de salir, fui amenazada de muerte y se me dijo que mi familia y mi hija iban a sufrir las consecuencias si yo hablaba. Hago responsable al gobierno mexicano...» (Ibid., p. 107).

Con insólita valentía, Bertha Alicia, «a quien habían desnudado brutalmente», denuncia al gobierno mexicano porque, dice, «creo que es necesario dejar claro que en México sí hay cárceles clandestinas y en ellas se encuentran cientos de desaparecidos políticos y comunes y que la tortura se practica sistemáticamente y con la mayor impunidad» (Id.).

Son cinco años durante los cuales Poniastowska rastrea los pasitos al trote de Rosario, quien va y viene de veintenas de ciudades en Estados Unidos, pregonando su causa (y ganando publicidad como chaqueta de teflón), y de ciudad en ciudad dentro de México, de oficina en oficina en la capital, hostigando interminablemente al presidente y sus lacayos y guaruras. No sólo se ha enterado de mucho más de lo que jamás hubiera querido saber sobre el grado y la cantidad de la homicida violencia gubernamental en su país, sino que ha comenzado a observar por todas partes la proliferación de guardaespaldas que todos los funcionarios públicos y los ricos traen 
consigo como perros guardián, quizás porque realmente corren el peligro de ser secuestrados o asesinados o -más probable- porque «estamos fabricando un país de pistoleros» y cochazos negros como signos de la inmortal sacralización de la violencia en México (Ibid., pp. 120-21): «Dan ganas de fabricar una bomba: X kilos de trilita, X kilos de plástico, $\mathrm{X}$ kilos de azúcar, porque el azúcar acelera la combustión, o de plano, unos cuantos kilitos de mexicana dinamita para hacer volar tanta insolencia y tanto rastacuerismo»(Ibíd., p. 121)

(Cuidado, Elena, no vayan a desaparecerte por saber los usos extracocineros del azúcar y el uso extra-burgués de la voz.)

Le perdonamos (y me perdonen) el tono satírico en medio de tanto horror, porque donde Elena Poniatowska sí aprovecha el poder de su propia voz sentimental, personal, adolorida, es en medio de su reportaje sobre el terco empeño de Rosario Ibarra por abrir un diálogo civil y democrático con el gobierno sobre el más que obvio hecho de la responsabilidad de éste por el secuestro, tortura, asesinato y encubrimiento del paradero de incontables víctimas. Culpables o inocentes, merecen su día en el tribunal, de acuerdo con la constitución y la magistratura.

Un día Poniatowska lee que el hijo de un amigo intelectual desaparece y pronto después su cadáver, con señas de tortura, se halla al lado de un camino. Lo «objetivo» de su investigación cronística, pese al aspecto emotivo relacionado con Rosario, de pronto se ha vuelto personal; lo que ha pasado a tantos «otros» mexicanos podría pasarle a ella, a Elena Poniatowska. Aquí, en el país que ella eligió llamar suyo y que ama con un ardor igual al que está consumiendo a Rosario por dentro con el fuego de la tortura de un condenado a la muerte (Ibíd., pp. 125-26). Y se da cuenta que el desprecio por la vida, que la violencia oficial convierte en trapo sangriento y tira como basura al lado del camino, es dirigida tanto hacia un individuo educado en la universidad como hacia un «Lucio Cabañas, Genaro Vásquez Rojas y Florencio Medrano Medares, que agotaron todos los cauces legales»; que lo que sucedió con el hijo de su amigo de la alta clase burguesa ha sucedido igualmente «con los miles de campesinos que vienen al Departamento Agrario, no les resuelven nada, y regresan a invadir tierras escopeta en mano» (Ibid., p. 98).

Con esta mención en medio del texto sobre «Los desaparecidos», Poniatowska establece otro vínculo interno con la última de las crónicas que conforman el libro, «La colonia Rubén Jaramillo», cuya recreación ficcionalizada de la invasión de tierra, "escopeta en mano", es metonimia, sinécdoque, emblema y alegoría en forma de poesía prosaica para las cuatro crónicas que pavimentan el camino al texto más extenso y, a su manera, más desgarrador de todos. Leer el testimonio de Rosario, ver por las descripciones líricas de Poniatowska a una madre que día con día y año tras año está convirtiéndose en pura pena y abstracción política, es a la vez una responsabilidad y un suplicio. Leer el testimonio de una madre que ha tenido que aguantar la triple tortura de ser desnudada violentamente mientras sabía que su hijita de un año observaba aquel horror y luego, para colmo, mirar mientras hombres bestiales torturaron a su bebé, no sólo es doloroso, es no poder contener las lágrimas. Presenciar a través de los ojos y la vida de los colonizadores de la fundación pacífica y violenta del pueblo Rubén Jaramillo, misión revolucionaria y democrática de Florencio Medrano Medares, el Güero, es caer absorto en la fascinación de lo verdadero presentado con la belleza de lo novelesco, perdernos en el suspenso de «un romance» (Manjarrez, op. cit., p. 111). Junto con los insólitos méritos del testimonio que Poniatowska recoge para este reportaje novelado, la historia romántica de una relación tímida de amor entre el Güero y Elena, la maestra que deja la escuela para servir de secretaria en la nueva colonia, nos atrae sinceramente porque, como bien dice Manjarrez, aquí voz y palabras de la autora «no dan una nota falsa jamás» (Id.).

No sabemos sino hasta las últimas páginas del libro que Poniatowska no presenció ninguno de los actos de fundación o defensa de la colonia, ni cuando el Güero por fin huyó armado justo minutos antes de que los agentes del gobierno pudieran capturarlo. Como en el caso de Noche y Hasta no verte, todo ha sido reconstruido con base en testimonios recogidos después, cuando (se supone que) el Güero ya ha muerto en campaña y su adelita Elena lo ha llorado. Lo que sí revela la historia es que, a diferencia de Rosario, cuyo proyecto de años es con base en la legalidad y una campaña paciente para tomar declaraciones contra el gobierno, el Güero Medrano funda colonias -la Jaramillo, por ejemplo- como el primer paso en una guerrilla extendida y como, según su lógica radicalizada, la única manera de «dialogar» con un gobierno que, sólo en el estado de Guerrero, ha desaparecido a 255
De la "muerte florida" al activism civil: Elena Poniatowska rompe el fuerte silencio ancestral LINDA EGAN 
El alcoholismo y la borrachera forman otro leitmotiv que recorre el libro; igual se destaca en el discurso de Sahagún y otros cronistas que detallan la vida cultural de los aztecas. Como ha observado Inga Clendinnen, las leyes que tienen una sociedad son buenos indicios de lo que hace regularmente una gente; las muchas leyes en contra de la borrachera y los muchos castigos (hasta la pena de la muerte) por emborracharse contra la ley en el México azteca son prueba de que había un gran problema con el abuso del alcohol. Ese problema empeoró después de la conquista y la pérdida de controles sociales sobre la vida organizada de los sobrevivientes indígenas.

De la «muerte florida" al activismo civil: Elena Poniatowska rompe el fuerte silencio ancestral LINDA EGAN campesinos (Poniatowska, Fuerte, p. 224), y que jamás -nunca- cumple con ninguna promesa a la gente. Sus palabras son veneno dulce vertido en los oídos de gente vulnerable, deliberadamente mantenida sin escolarización y fácilmente manipulada. El Güero aconseja a los colonos que no tomen en serio nada de lo que el gobierno o los terratenientes les diga, porque siempre van a terminar engañados.

El Güero tiene razón, pero no sin que los campesinos que intenta aleccionar en una especie de autogobierno -la sociedad civil, democrática- le descrean porque es más bonito aceptar que el gobierno les dará el agua $\mathrm{y}$ herramientas y otras cosas prometidas si tan sólo entregan las armas que esconden en la colonia. Así es que el hermano del Güero y otros de los líderes son capturados, torturados y muertos, y el Güero disparado de tal forma que -el discurso así lo sugiere- muere.

Lo que no muere con él son las lecciones que había enseñado a los colonos acerca de la organización y la manera de trabajar colectivamente un día de la semana para el bien de todos. Fue muy importante cómo, sencillamente por escuchar a las mujeres, preguntar acerca de sus sentimientos y sus vidas, les mostraba la manera de resistir la violencia machista de sus maridos, sobre todo cómo quitarles el alcohol y la borrachera constan$\mathrm{te}^{28}$, y de demandar tiempo y espacio para desenvolverse como individuos, como seres humanos; cómo, en fin, era posible que los más pobres y miserables de la tierra pudieran reclamar un lugar decente donde sus hijos conocieran el bienestar físico y emocional, el beneficio de una educación de primaria, y algo de estabilidad en los años formativos de su vida. Años después de la muerte del Güero Medrano, cuando casi nadie en la colonia Rubén Jaramillo recordaba quién era, Elena Poniatowska se encuentra allí y conoce a una mujer que sí lo había conocido y que lo recordaba todo....Y nos conmueve saber que la violencia sagrada de México reclamó otra víctima sacrificial más antes de que pudiera ver florecer el jardín que había sembrado con la vehemencia de su saber, querer y creer. «No den las graciaaaaaas, no deeeeeeen las graciaaaaaaaas», bramaba el Güero cuando escuchaba cómo los colonos agradecían a los agentes del gobierno que trajeran regalos para engatusar a los campesinos y convencerlos a entregar sus armas. El Güero les dijo

que aquello que les enviaban de la capital no era un regalo sino el producto de años, que todo eso, el agua, la luz, los postes, los desayunos escolares ya estaban pagados de antemano, que eran la sangre de sus abuelos, el polvo de los huesos, el mástil de sonajas de la mazorca, el grano lanzado en los surcos; que sólo entraban en posesión de lo que debió ser suyo hace mil años, que al que tenían que dar el crédito era a su corazón porque la tierra era su casa (Ibid., p. 227).

Y sí, tiene razón el Güero. Desde que el tlatoani mexica mantenía con hambre al macehualli esclavizado, el agua, la luz, el desayuno, la educación y la tierra le pertenecían al mexicano, quien no le debía las gracias al mandatario sino al revés, el jefe le debía gracias a los que labran la tierra que lo hacía rico a él. Eso y más el Güero enseñaba a sus colonos, y más, mucho más, a las esposas de aquellos hombres. Eso, antes de irse, impacientemente, a sumarse a la violencia, porque «cuando la vida no vale nada, no hay miedo a la muerte» (Ibid., p. 260). Va en busca de ella, el Güero, secuestrando a ricos, asesinando gente, recogiendo fondos para los colonos. "Nada como la muerte en guerra / nada como la muerte florida'» (Ibid., p. 275), viene la frase prehispánica, alusión al guerrero que batalla no para matar sino para capturar víctimas para sacrificar, o para ser sacrificado él mismo. Parece que el Güero ganó lo que se buscaba. Se sacrifica para la causa, dejando como legado todo un pueblo de miles de gente que viven decentemente -y un buen número de mujeres mejor preparadas para defenderse en un mundo hecho por y para machos.

Si nos sorprende que uno de esos machos, tan dispuesto a morir mexicanamente, les diera lecciones feministas a mujeres pobres del campo (Ibid., p. 231), admiramos que una mujer como Rosario Ibarra haya podido trasmutar su dolor personal en una causa internacional que beneficie a su sociedad entera. Por la voluntad de actuar, de intentar vencer el cinismo deshumanizador de siglos, ella y las mujeres que la respaldan han instruido a hombres corruptos, crueles, criminales, sobre la manera de hacerse una sociedad moderna de leyes, una sociedad civil (Ibíd., pp. 88, 117, 143). Dice Poniatowska:

Si Rosario Ibarra de Piedra no hubiera iniciado una campaña de protesta y de difusión, no estaríamos enterados a la fecha del problema de los desaparecidos y sólo tendríamos una noción muy vaga y fácilmente desechable de cómo, en casos de oposición política, son pisoteadas en nuestro país las libertades democráticas (Ibíd., p. 143). 
Y, cual Bernal Díaz del Castillo posmoderno, Elena Poniatowska lucha contra un gobierno que ningunea hasta borrar la existencia de los que se le oponen en opinión o acción. Clama justicia la lista de los héroes, de las víctimas, de los que han pagado el precio de «entrada libre» en la sociedad que se organiza: los héroes de 1968 (Ibíd., pp. 50, 53-55, 57-59), los líderes de maestros, ferrocarrileros y campesinos (Ibíd., p. 98), los torturados que milagrosamente reaparecen (Ibíd., pp. 105-15), los que ayudaron a fundar la colonia Rubén Jaramillo (Ibíd., pp. 181-278).

Las personas que poseen estos nombres anuncian el mensaje que se oye claramente en cada uno de los segmentos de Fuerte es el silencio: los ciudadanos, individual y colectivamente, tienen que responsabilizarse por volver auténticas las leyes avaladas por la constitución de su país. De hecho, los ciudadanos son responsables por darle sentido a la propia constitución, la cual, sin su vigilancia y trabajo, es solamente un pedazo de papel, sonido y furia que nada significa. Es Rosario y Bertha y el Güero Medrano quienes tienen la responsabilidad moral, ética, política y personal de forzar a los seres humanos que ocupan puestos en el gobierno -el gobierno de, por, y para la gente- a reconocer y respetar los derechos civiles y humanos de cada uno de los mexicanos.

Elena Poniatowska lo ha hecho ya, en escribir Fuerte es el silencio y romper el mutismo de los que han sido callados por tantos siglos a través de tantos dolores y muertes. Hace un milenio la carne humana en México valía lo que el maíz y la sangre humana se veía igual que la lluvia y el agua del río (Clendinnen, op. cit., p. 208). Pero, dice Elena, para todos los del silencio roto ya: hoy yo no soy una mazorca de maíz. Soy un ser humano. Tengo derecho a mi humanidad. Me la reclamo de mi gobierno. Y si no me la da ahorita y gratuito, le mando a cada uno en el gobierno una calavera de azúcar con su nombre escrito bien clarito. Sufragio Efectivo. No Elección.

\section{OBRAS CITADAS}

José Alcina Franch, «Poder y sociedad», Azteca-Mexica: las culturas del México antiguo, José Alcina Franch, Miguel LeónPortilla y Eduardo Matos Moctezuma (eds.), Barcelona y Madrid, Lunwerg Editores, 1992, pp. 161-71.
Ana María Amar Sánchez, «Las voces de los otros: el género de no-ficción en Elena Poniatowska», Filología, 25:1-2 (1990), pp. 161-74.

Pierina E. Beckman, «Las crónicas de Elena Poniatowska», Fem, 16: 110 (1992), pp. 45-47.

José Joaquín Blanco, Crónica literaria: un siglo de escritores mexicanos, México, $\mathrm{Cal}$ y Arena, 1996.

Johanna Broda, «Templo Mayor as Ritual Space», en Johanna Broda, Davíd Carrasco y Eduardo Matos Moctezuma, The Great Temple of Tenochtitlan: Center and Periphery in the Aztec World, Berkeley, University of California Press, 1987, pp. 61-123.

Louise M. Burkhart, The Slippery Earth: Nabua-Christian Moral Dialogue in Sixteenth-Century Mexico, Tucson, University of Arizona Press, 1989.

Barry Carr, Marxism and Communism in Twentieth-Century Mexico, Lincoln \& London, University of Nebraska Press, 1992.

Bernal Díaz del Castillo, Historia verdadera de la conquista de la Nueva España, México, Alianza, 1991.

Pablo Escalante, «Vivir en Tenochtitlan», en José Alcina Franch, Miguel León-Portilla y Eduardo Matos Moctezuma (eds.), Azteca-Mexica: las culturas del México antiguo, Barcelona y Madrid, Lunwerg Editores, 1992, pp. 371-86.

Claudia Fermán, «México en la posmodernidad: textualización de la cultura popular urbana». Nuevo Texto Crítico, 4 (1991), pp. 157-67.

Jean Franco, Historia de la literatura bispanoamericana a partir de la Independencia, trad. Carlos Pujol. 7a ed., Barcelona, Seix Barral, 1987.

Magdalena García Pinto, «Elena Poniatowska». Entrevista, en Women Writers of Latin America: Intimate Histories, trad. Trudy Balch \& Magdalena García Pinto, Austin, University of Texas Press, 1991, pp. 162-81.

Héctor Manjarrez, «La indiscreción de Elena Poniatowska», Cuadernos Políticos, 30 (1981), pp. 102-14.

Miguel León-Portilla, Literaturas indígenas de México, México, Editorial MAPFRE/ Fondo de Cultura Económica, 1992.

Samuel Martí, Canto, danza y música precortesianos, México, Fondo de Cultura Económica, 1961.
De la «muerte florida" al activismo civil: Elena Poniatowska rompe el fuerte silencio ancestral INDA EGAN 
Michael Meyer, D., \& William L. Sherman. The Course of Mexican History, $4^{\mathrm{a}}$ ed., New York-Oxford, Eng., Oxford University Press, 1991.

Carlos Monsiváis, Entrada libre: crónicas de la sociedad que se organiza, México, Era, 1987.

- "Mira, para que no comas olvido...': las precisiones de Elena Poniatowska», en La Cultura en México, 1007 (1981), pp. 2-5.

Gabriela Mora, «Notas teóricas en torno a las colecciones de cuentos integrados", Revista Chilena de Literatura, 42 (1993), pp. 131-37.

Rocío Oviedo Pérez de Tudela, «Los cuerpos del disfraz. Madre o amante. La narrativa de Elena Poniatowska», Literatura Mexicana, 16 (2005), pp. 153-65.

Elena Poniatowska, Fuerte es el silencio, México, Era, 1980.

- Nada, nadie: las voces del temblor, México, Era, 1988.

- La noche de Tlatelolco: testimonios de historia oral, México, Era, 1971.
Sara Poot Herrera, «Las crónicas de Elena Poniatowska», La Colmena, 11 (1996), pp. 17-22.

Fray Bernardino de Sahagún, Historia general de las cosas de Nueva España, 2 vols., intr. Alfredo López Austin y Josefina García Quintana, Madrid: Alianza Universidad, 1988.

Laurette Séjourné, Pensamiento y religión en el México antiguo, México y Buenos Aires, Fondo de Cultura Económica, 1957.

Diana Sorensen, «Tlatelolco 1968: Paz and Poniatowska on Law and Violence», Mexican_Studies/Estudios Mexicanos, 18 (2002), pp. 297-321.

William K. Stevens, «An Eden in Ancient America? Not Really», New York Times, 30 mar. 1993, B7, B10.

Richard Townsend, The Aztecs, London, Thames and Hudson, 1992.

Verónica Volkow, Reseña de Fuerte es el silencio de Elena Poniatowska. "Crónicas del silencio", Revista de la Universidad de México n. e. 36.4 (1981), pp. 41-42.
De la «muerte florida» al activismo civil: Elena Poniatowska rompe el fuerte silencio ancestral LINDA EGAN 